Aim of the study: The aim of the study was to evaluate the effectiveness of postoperative radiotherapy in prostate cancer patients with unfavorable prognostic factors.

Material and methods: In the years 2002-2008, 121 consecutive prostate cancer patients underwent radical prostatectomy and postoperative radiotherapy. The median dose was 64 Gy (range: 6072 Gy). Biochemical and clinical progression-free survival were estimated. Univariate and multivariate analyses were used to analyze clinicopathological variables associated with treatment failure. Results: The median follow-up was 27 months. Three-year bPFS was $72 \%$. On univariate analysis it was influenced by: extracapsular tumor extension $(60 \%$ vs. $75 \%, p=0.0232$ ), seminal vesicles invasion (52\% vs. $85 \%, p=0.00041$ ), Gleason score $\geq 7(65 \%$ vs. $86 \%, p=0.044)$ and the use of hormonal therapy ( $50 \%$ vs. $80 \%$, $p=0.0058)$. On multivariate analysis bPFS was associated with: TNM stage $(H R=3.19)$, postoperative hormonal therapy $(H R=2.6)$, total irradiation dose $(H R=0.82)$ and the maximum pretreatment level of prostate-specific antigen (PSA) $(H R=0.95)$. Three-year cPFS was $84 \%$. On univariate analysis it was influenced by: preoperative PSA level $>10 \mathrm{ng} / \mathrm{ml}$ ( $75 \%$ vs. $90 \%, p=0.04$ ), vascular-nerve bundles involvement (63\% vs. $88 \%$, $p=0.0031$ ), adjacent organs infiltration ( $50 \%$ vs. $85 \%, p=0.018$ ) and the use of postoperative hormonal therapy ( $62 \%$ vs. $90 \%, p=0.02$ ). On multivariate analysis CPFS was associated with: TNM stage $(\mathrm{HR}=2.68)$, postoperative hormonal therapy $(H R=3.61)$ and total irradiation dose $(\mathrm{HR}=0.78)$.

Conclusions: Postoperative radiotherapy in patients with unfavorable prognostic factors provides good biochemical and local control. Total irradiation dose and postoperative hormonal therapy are important treatment factors influencing prognosis.

Key words: prostate carcinoma, radical prostatectomy, postoperative radiotherapy

Contemp Oncol (Pozn) 2013; 17 (5): 413-420 DOI: $10.5114 /$ wo.2013.37215

\section{The role of postoperative radiotherapy in prostate cancer patients}

\author{
Małgorzata Zarzycka ${ }^{1}$, Ewa Ziółkowska', Tomasz Wiśniewski ${ }^{1}$, \\ Wiesława Windorbska ${ }^{2}$, Agnieszka Żyromska ${ }^{2,3}$, Zbigniew Wolski ${ }^{4}$
}

1Department of Radiotherapy I, Oncology Centre - prof. Franciszek Łukaszczyk Memorial Hospital, Bydgoszcz, Poland

2Department of Teleradiotherapy, Oncology Centre - prof. Franciszek Łukaszczyk Memorial Hospital, Bydgoszcz, Poland

${ }^{3}$ Chair and Clinic of Oncology and Brachytherapy, Ludwik Rydygier Collegium Medicum in Bydgoszcz, Nicolaus Copernicus University in Torun, Poland

${ }^{4}$ Chair and Department of General, Oncologic and Pediatric Urology, Ludwik Rydygier Collegium Medicum in Bydgoszcz, Nicolaus Copernicus University in Torun, Poland

\section{Introduction}

Despite the increased level of diagnostic methods, a significant number of prostate carcinoma cases are still detected in advanced stages. Radical prostatectomy is a basic method of prostate carcinoma treatment [1-5]. Surgical treatment provides perfect control in cases of patients with cancer limited to the organ (stage T1-T2) [6]. However, in about $38-52 \%$ of patients treated with prostatectomy, unfavorable prognostic factors [7, 8], such as extracapsular extension (ECE), seminal vesicles invasion (pT3b stage) or positive surgical margins $(\mathrm{SM}+)$, are observed and are considered to influence local control [9-11]. The pathological T3 stage is connected with $67 \%$ risk of biochemical failure appearing in a period of 5 years observation after prostatectomy [12]. In 50\% of cases clinical symptoms of local recurrence develop and in about $30 \%$ of cases distant metastases appear [13-15].

Positive surgical margins constitute a prognostically important factor [11, 16]. The percentage of patients with microscopically positive margins (R1) in stage $\mathrm{T} 2$ is $5-10 \%$, but in stage $\mathrm{T} 3$ it increases to $10-40 \%$ [17]. The meaning of R1 status in T2 stage is widely discussed, while in T3 it is considered an independent factor of biochemical progression. In about $60 \%$ of cases defined as pT3-R1 PSA increases during 5 years, often with no clinical symptoms [11]. On the other hand, in 35-40\% of asymptomatic patients with PSA increasing after radical prostatectomy, the recurrence appears in an area of postoperative anastomosis and is revealed by biopsy [18].

Radiotherapy has been widely used after prostatectomy for years. Its aim is to sterilize the cancer cells in the prostate bed and thus to decrease the risk of local and biochemical recurrence. Apart from a number of retrospective studies, three randomized studies proved that implementation of postoperative radiotherapy in patients with high risk of recurrence has an influence on improving biochemical progression-free survival (bPFS) and clinical progression-free survival (CPFS) [19-24]. An improvement of overall survival after the use of adjuvant radiotherapy was proved in the SWOG study [22].

\section{Material and methods}

In the years 2002-2008, 121 consecutive prostate cancer patients underwent radical prostatectomy and postoperative radiotherapy. Radiotherapy was indicated by stage T3 (extracapsular extension or seminal vesicles invasion) and/or positive surgical margins. Patients with postoperative PSA level above $0.2 \mathrm{ng} / \mathrm{ml}$ were excluded. Imaging tests were not performed routinely before radiotherapy. After surgery hormonal therapy was given to 30 patients by urologists according to individual indications. Median patients' age at the 
Table 1. Characteristics of patients

\begin{tabular}{|c|c|}
\hline Feature & Value \\
\hline $\begin{array}{l}\text { Average patient's age } \\
\text { Median patients' age }\end{array}$ & $\begin{array}{l}62.28 \text { years (range: } 45-81 \text { ) } \\
62 \text { years (range: } 45-81 \text { ) }\end{array}$ \\
\hline $\begin{array}{l}\text { Average preoperative PSA level }(\mathrm{ng} / \mathrm{ml}) \\
\text { Median preoperative PSA level }(\mathrm{ng} / \mathrm{ml})\end{array}$ & $\begin{array}{l}13.77 \text { (range: } 0.28-102) \\
10 \text { (range: } 0.28-102)\end{array}$ \\
\hline $\begin{array}{l}\text { Pathological TNM stage } \\
\text { pT2c } \\
\text { pT3a } \\
\text { pT3b } \\
\text { pT4 } \\
\text { pNO } \\
\text { pN }(+)\end{array}$ & $\begin{array}{l}2(1.6 \%) \\
69(55.2 \%) \\
48(38.4 \%) \\
6(5 \%) \\
112(93 \%) \\
9(7 \%)\end{array}$ \\
\hline $\begin{array}{l}\text { Gleason score } \\
\text { average } \\
\text { median } \\
2-6 \\
7-9\end{array}$ & $\begin{array}{l}6.6 \\
7 \\
49(40 \%) \\
72(60 \%)\end{array}$ \\
\hline $\begin{array}{l}\text { Extracapsular tumor extension } \\
\text { Seminal vesicles invasion } \\
\text { Vascular-nerve bundles infiltration } \\
\text { Positive surgical margins } \\
\text { Adjacent organs infiltration }\end{array}$ & $\begin{array}{l}93(77 \%) \\
51(42 \%) \\
42(35 \%) \\
26(21 \%) \\
6(5 \%)\end{array}$ \\
\hline $\begin{array}{l}\text { Hormonal therapy before surgery } \\
\text { Hormonal therapy after surgery }\end{array}$ & $\begin{array}{l}12(10 \%) \\
30(25 \%)\end{array}$ \\
\hline $\begin{array}{l}\text { Average total irradiation dose (Gy) } \\
\text { Median total irradiation dose (Gy) }\end{array}$ & $\begin{array}{l}64.45 \text { (range: } 56-72) \\
64 \text { (range: } 56-72 \text { ) }\end{array}$ \\
\hline $\begin{array}{l}\text { Median time between surgery and } \\
\text { radiotherapy }\end{array}$ & $\begin{array}{l}1.8 \text { months } \\
\text { (range: } 0.03-8.5 \text { ) }\end{array}$ \\
\hline Median follow-up & $\begin{array}{l}27.4 \text { months } \\
\text { (range: } 3.5-108.3 \text { ) }\end{array}$ \\
\hline
\end{tabular}

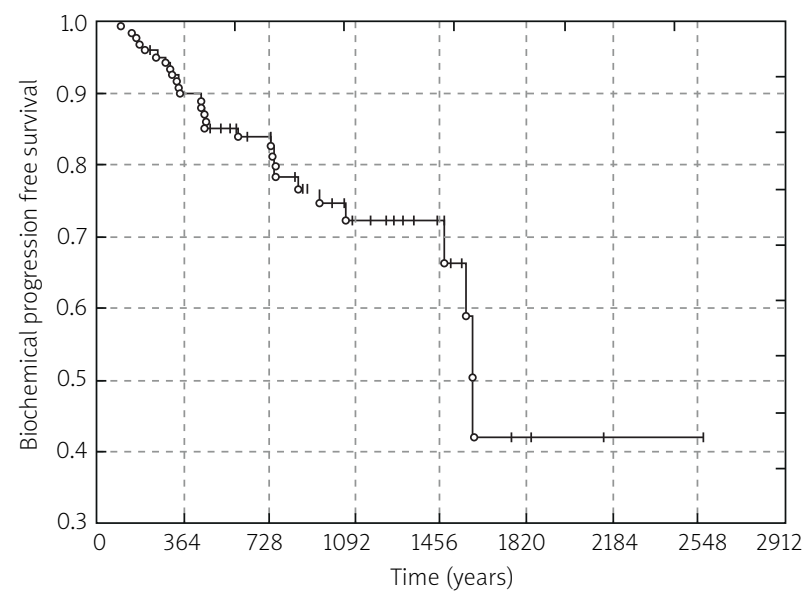

Fig. 1. Results of Kaplan-Meier analysis of biochemical progression-free survival (bPFS)

beginning of radiotherapy was 62 years (range: $45-81$ ). Characteristics of patients are presented in Table 1.

All patients underwent radiotherapy with the use of a linear accelerator equipped with a multileaf collimator and generating photons of $15 \mathrm{MV}$ energy. The median time between prostatectomy and the beginning of radiotherapy was 1.8 months (range: 0.031-8.5). The prostate and seminal vesi- cles postoperative bed was the irradiation target (CTV - clinical target volume) drawn by the radiation oncologist on the CT scans performed for treatment planning. Planning target volume (PTV) was created by adding a $10 \mathrm{~mm}$ margin to the CTV. The median dose given to the PTV was 64 Gy (range: 60-72 Gy). During the period of radiotherapy the patients were examined once a week. The first post-treatment examination was conducted a month after the treatment. Further examinations were conducted every three months for the next three years and then every six months. PSA levels were checked during each control visit. Imaging examinations were performed in the case of patients suspected of clinical or biochemical recurrence. Biochemical recurrence was defined by PSA increase over $0.2 \mathrm{ng} / \mathrm{ml}$ (second result exceeding this limit). Clinical recurrence was differentiated into local or distant. In case of suspected local recurrence magnetic resonance imaging (MRI) of the pelvis was conducted together with biopsy of detected changes and/or biopsy of urethrabladder anastomosis. Distant spread of the disease was diagnosed by image tests (bone scan, X-rays, computed tomography $(C T)$, ultrasonography of lymph nodes). Bone metastases were proven by 18F-FDG positron emission tomography (PET) in two patients, because bone scans in these cases were not diagnostic. The biochemical progression-free time was defined as from the day of surgery to the date of the second result exceeding the limit of $0.2 \mathrm{ng} / \mathrm{ml}$. The clinical progression-free time was defined as from the day of surgery to the date of the image or histopathological test confirming the recurrence. Primary endpoints were biochemical progression-free survival (bPFS) and clinical progression-free survival (CPFS) and were estimated using the Kaplan-Meier method. As a secondary endpoint the influence of the following clinicopathological variables on recurrence was evaluated: patient's age, maximum preoperative PSA level, pathological grade according to the Gleason scale, vascular-nerve bundles infiltration, extracapsular tumor extension, seminal vesicles invasion, positive surgical margins, total dose of irradiation and the use of hormonal therapy. For this purpose univariate (log-rank test) and multivariate analyses (Cox's regression) were used. $P$ value of 0.05 was defined as statistically significant. The statistical analysis was proceeded with the use of Statistica program ver. 9.0.

\section{Results}

The median follow-up was 27 months (range: 3.5-108.3). Three-year bPFS was 72\% (Fig. 1).

The univariate analysis proved that bPFS was influenced by the following factors: extracapsular tumor extension (60\% vs. 75\%, $p=0.0232$ ) (Fig. 2A), seminal vesicles invasion (52\% vs. $85 \%, p=0.00041$ ) (Fig. 2B), Gleason score $\geq 7$ (65\% vs. $86 \%, p=0.044$ ) (Fig. 2 C) and the use of hormonal therapy (50\% vs. $80 \%, p=0.0058$ ) (Fig. 2D). Such factors as maximum preoperative PSA level, positive surgical margins, adjacent organs infiltration and irradiation dose did not significantly influence bPFS. Table 2 presents bPFS depending on the risk factors included in the univariate analysis.

According to the multivariate analysis, the following factors influenced bPFS: pTNM stage ( $\mathrm{HR}=3.19, p=0.007)$, adjuvant hormonal therapy $(\mathrm{HR}=2.6, p=0.02)$, total irradiation 


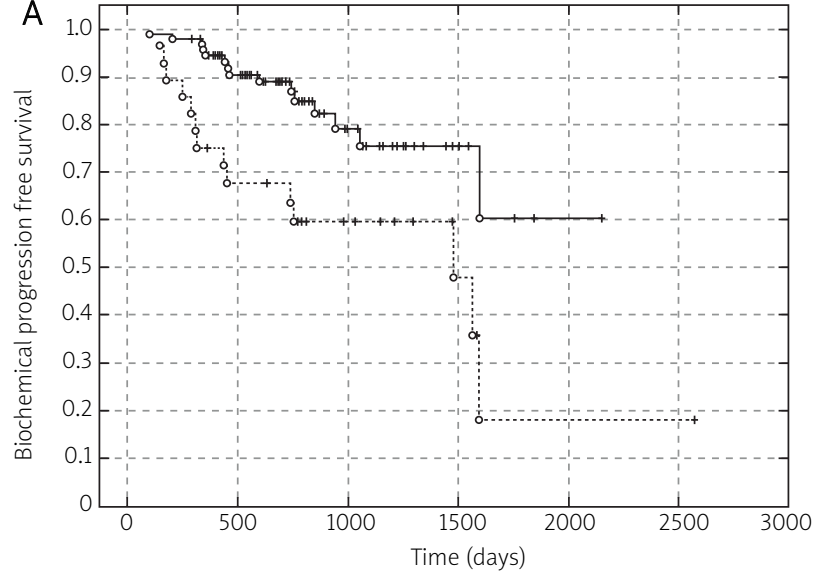

log-rank test

$p=0.0232$

extracapsular extension

no

-... yes

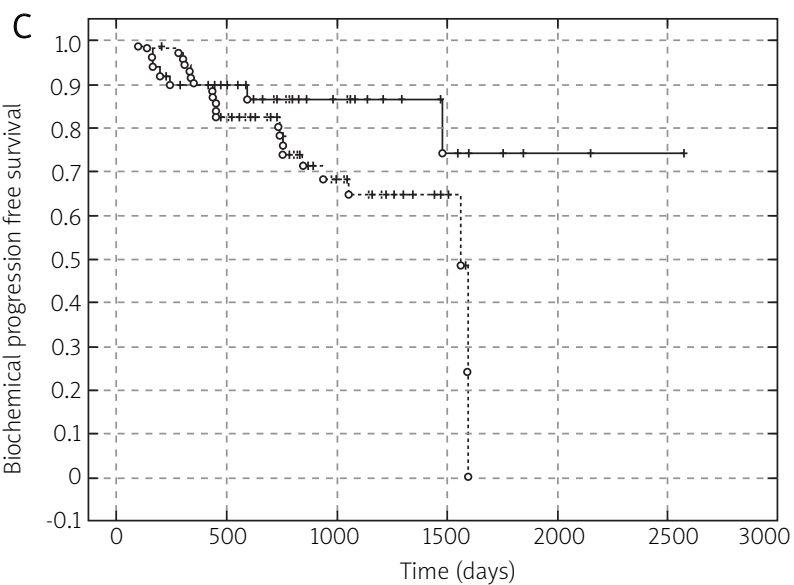

log-rank test

$p=0.044$

Gleason score

- 2-6

- . - - 7-10

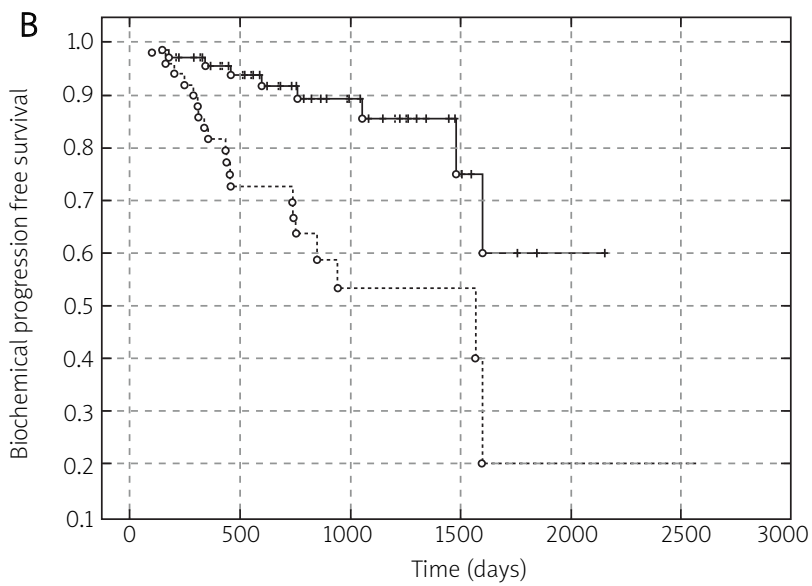

log-rank test

$p=0.0041$

seminal vesciles invasion

no

-... yes

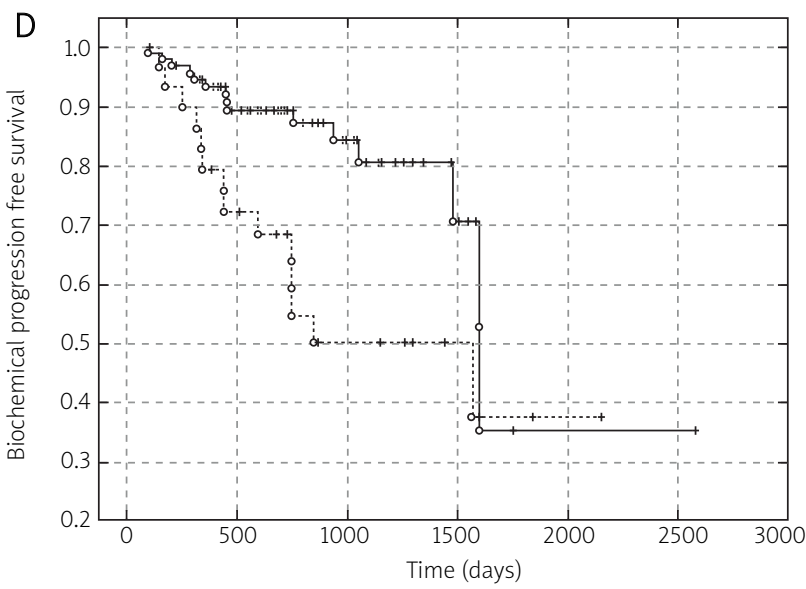

log-rank test

$p=0.005$

adjuvant hormonal therapy

- no

... yes

Fig. 2. Results of Kaplan-Meier analysis of bPFS depending on: A) the presence or absence of extracapsular extension; B) the presence or absence of seminal vesicles invasion; C) Gleason score; D) the use or lack of adjuvant hormonal therapy

dose used in the postoperative treatment $(\mathrm{HR}=0.82, p=$ $=0.02)$ and the maximum pretreatment level of PSA (HR = $=0.95, p=0.05)$ (Table 3).

When in the multivariate analysis we included histopathological data only, the most significant parameter influencing the risk of biochemical progression was the invasion of seminal vesicles $(\mathrm{HR}=2.86, p=0.02)$ (Table 4$)$.

Biochemical recurrence was noted in 29 (24\%) out of all analyzed cases and appeared 3-52 months (median: 15 months) after the day of surgery. Among them in 18 (62\%) cases clinical recurrence was diagnosed. In 13 patients biochemical progression preceded clinical recurrence, on average by 5 months. In the remaining 5 patients biochemical and clinical progression appeared at the same time. In 3 cases the clinical recurrence involved the tumor bed and in the other 15 cases distant metastases appeared, mainly to the bones (11 cases) and in individual cases to the lung, brain, liver and supraclavicular lymph nodes.

Three-year clinical progression-free survival (CPFS) was 84\% (Fig. 3)

The univariate analysis proved that CPFS was influenced by the following factors: preoperative PSA level $>10$ ng/ml (75\% vs. 90\%, $p=0.04)$ (Fig. 4A), vascular-nerve bundles involvement ( $63 \%$ vs. $88 \%, p=0.0031$ ) (Fig. 4B), adjacent organs infiltration ( $50 \%$ vs. $85 \%, p=0.018$ ) (Fig. 4C) and the use of postoperative hormonal therapy ( $62 \%$ vs. $90 \%$, $p=0.02$ ) (Table 2, Fig. 4D).

According to the multivariate analysis, CPFS was influenced by such factors as TNM stage ( $\mathrm{HR}=2.68, p=0.005)$, postoperative hormonal therapy $(\mathrm{HR}=3.61, p=0.02)$ and total irradiation dose used in the postoperative treatment $(\mathrm{HR}=0.78, p=0.03)$ (Table 3). 
Table 2. Dependence of bPFS and cPFS on progression risk factors - univariate analysis results

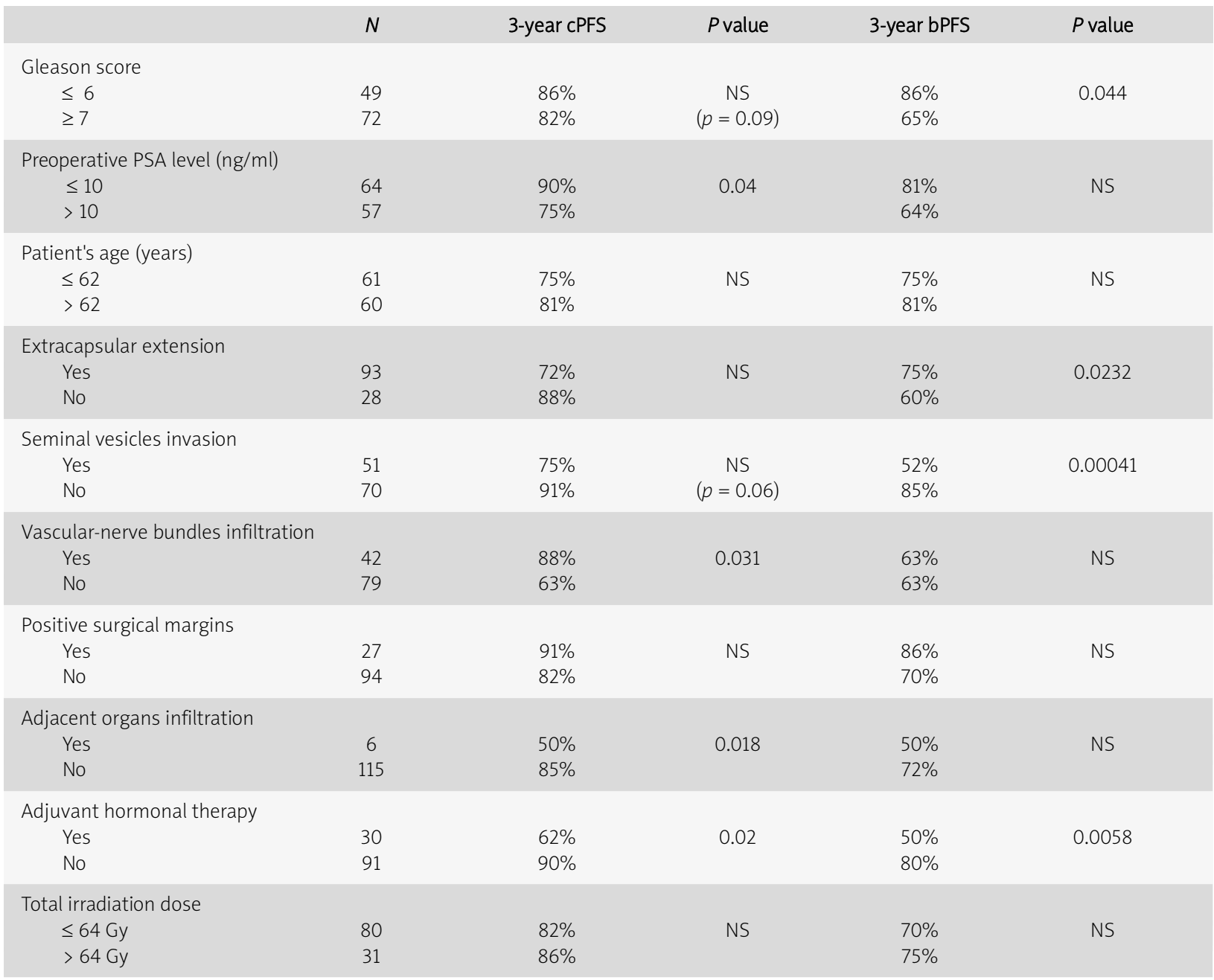

Table 3. Dependence of bPFS and cPFS on progression risk factors - multivariate analysis results (Cox regression)

\begin{tabular}{|c|c|c|c|c|}
\hline & \multicolumn{2}{|c|}{ CPFS } & \multicolumn{2}{|c|}{ bPFS } \\
\hline & hazard ratio & $P$ value & hazard ratio & $P$ value \\
\hline Patient's age & 0.93 & 0.08 & 0.9 & 0.17 \\
\hline pTNM stage & 2.68 & 0.005 & 3.1 & 0.00018 \\
\hline Gleason score & 1.46 & 0.11 & 1.2 & 0.01 \\
\hline Neoadjuvant hormonal therapy & 0.49 & 0.42 & 1.3 & 0.60 \\
\hline Adjuvant hormonal therapy & 3.61 & 0.02 & 2.6 & 0.02 \\
\hline Maximum preoperative PSA level & 0.95 & 0.13 & 0.95 & 0.05 \\
\hline Total radiation dose & 0.78 & 0.03 & 0.82 & 0.02 \\
\hline
\end{tabular}

Table 4. Influence of histopathological parameters on bPFS results of multivariate analysis

\begin{tabular}{|lcc|}
\hline & Hazard ratio & Pvalue \\
\hline Extracapsular extension & 0.59 & 0.22 \\
\hline Seminal vesicles invasion & 2.86 & 0.02 \\
\hline Vascular-nerve bundles infiltration & 0.67 & 0.40 \\
\hline Positive surgical margin & 0.72 & 0.57 \\
\hline Adjacent organs infiltration & 2.75 & 0.11 \\
\hline Positive lymph nodes & 0.96 & 0.96 \\
\hline
\end{tabular}

\section{Discussion}

Postoperative, adjuvant radiotherapy of patients after prostatectomy has been controversial for years. Some authors have claimed that in patients with unfavorable prognostic factors it should be performed immediately after surgery [14, 26, 27, 30], while others have advised to wait until the PSA is increased or until biopsy confirms local recurrence [31, 32]. However, external beam irradiation has been widely used as a postoperative method of treatment. Approximately in about $30-50 \%$ of patients with a tumor clinically limited to the prostate, evaluation of postoperative mate- 
rial shows infiltration of the prostate capsule. Standard indications for postoperative irradiation include pT3 stage (extracapsular extension, seminal vesicles invasion), positive surgical margins and a detectable level of PSA after three weeks following surgery. The last indication is justified by the fact that $50 \%$ of patients with enduring PSA have a positive result of biopsy of urethra-bladder anastomosis.

A number of nonrandomized retrospective studies have been conducted in order to evaluate the role of postoperative radiotherapy. Their results proved that in the case of patients treated with postoperative radiotherapy it is possible to achieve even 95-100\% local control [14, 33-36] and a dose of 60 Gy significantly influences asymptomatic survival [37-42].

The use of postoperative radiotherapy after radical prostatectomy in the pT3 stage significantly limits local recur-

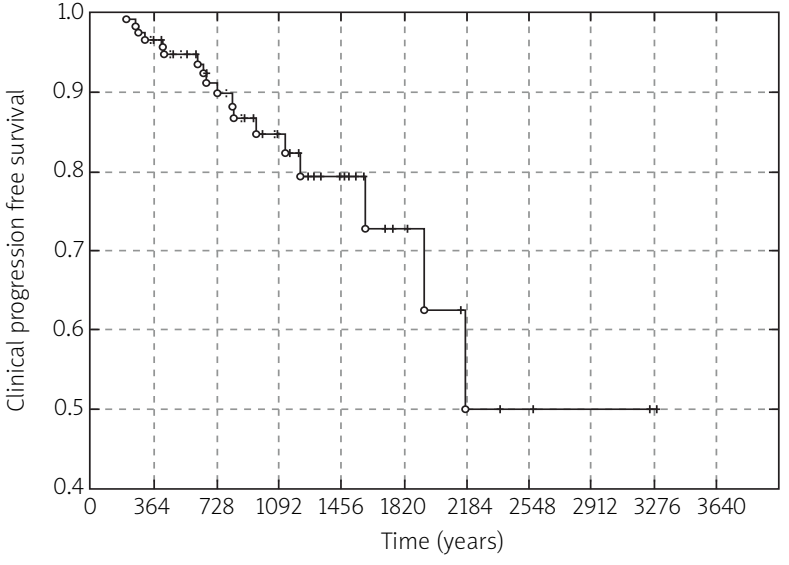

Fig. 3. Results of Kaplan-Meier analysis of clinical progressionfree survival (cPFS)
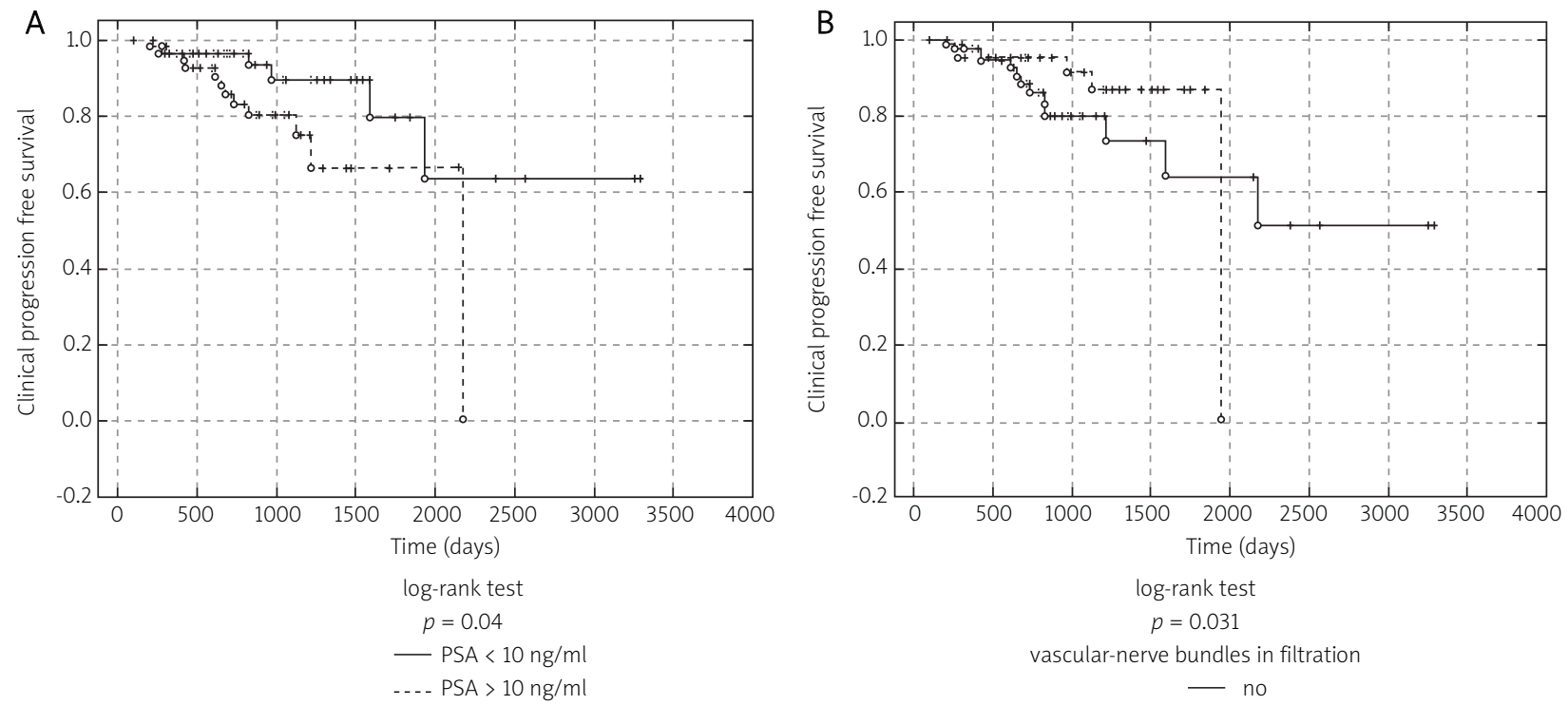

vascular-nerve bundles in filtration

$$
\text { - no }
$$
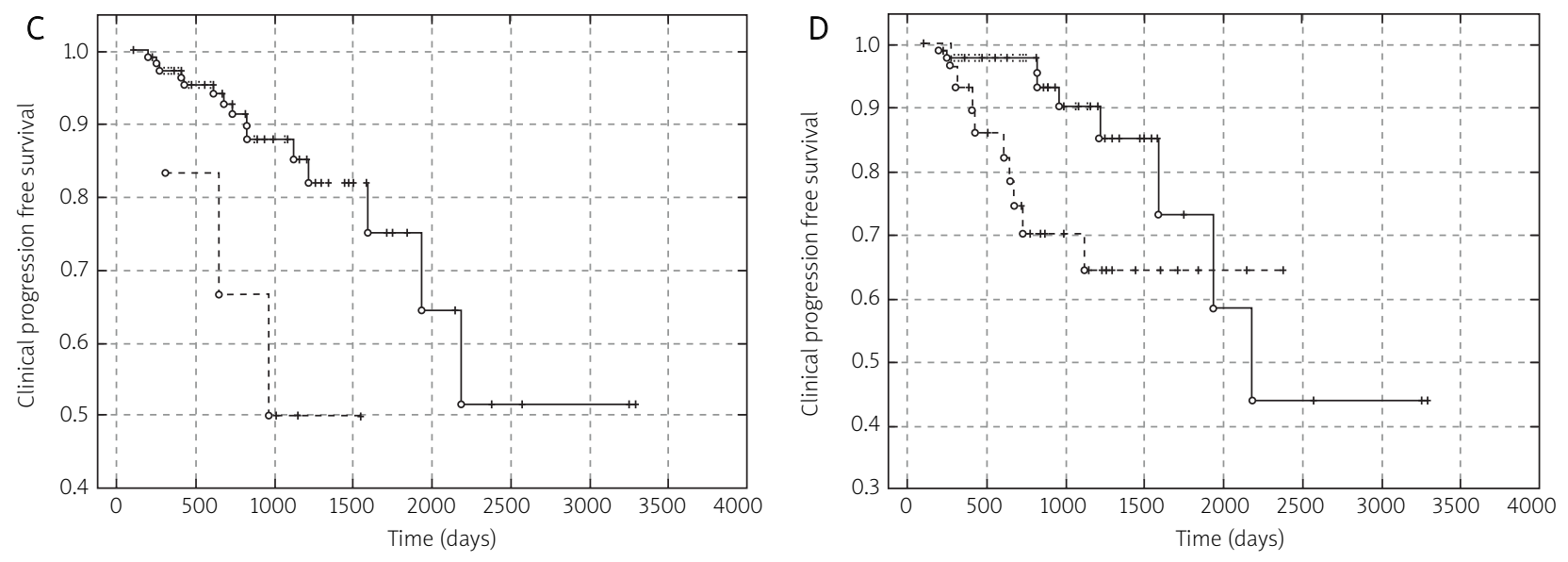

log-rank test

log-rank test

$$
p=0.005
$$

adjvant hormonal therapy

- no

...- yes

Fig. 4. Results of Kaplan-Meier analysis of cPFS depending on: A) preoperative PSA level; B) the presence or absence of vascular-nerve bundles infiltration; C) the presence or absence of adjacent organs infiltration; D) the use or lack of postoperative hormonal therapy 
rence. During 10-year observation of a group of 46 patients Anshers et al. noted over 30\% reduction of local recurrences, which was a result of using postoperative radiotherapy (40\% vs. $8 \%$ ). Also the percentage of 10 -year asymptomatic survival in patients treated with postoperative radiation was significantly higher (55\% vs. 37\%). However, no increase of overall survival was confirmed [14, 43].

Schild et al. and Nudell et al. made a retrospective evaluation of immediate postoperative radiotherapy in patients with PSA increasing after surgery. Postoperative radiotherapy (in case of positive surgical margin or pT3) enabled 5780\% 5-year disease-free survival [30, 37, 44].

Valicenti et al. estimated the influence of irradiation dose on risk of recurrence in a group of 86 patients. Radiotherapy using doses of 55-70.2 Gy (average: 64.8 Gy) was applied within 3-6 months after prostatectomy. Among 52 patients with PSA undetectable before radiotherapy, better control appeared in cases of patients given 61.5 Gy or more than in a group with lower doses (91\% vs. 57\%) [26, 39].

Petrovich et al. published results of a study conducted on 432 patients with stage T3NO cancer. Sixty-nine percent of the patients did not experience recurrence during 5 -year follow-up. In the multivariate analysis Gleason score and pTNM stage were independent factors influencing asymptomatic survival. Results of T3bNO patients with Gleason score of 7-10 were significantly worse. In this group probability of recurrence was 5.3 times higher than for patients with T3a and Gleason score 2-6 (4). Caraffini et al. reported results of a nonrandomized study conducted on 97 patients among whom 41 underwent adjuvant radiotherapy and 56 underwent salvage radiotherapy after PSA increase. Five-year disease-free survival in the whole group was 53\% and in the group with postoperative radiotherapy it was 76\% [35]. Similar results were obtained by other researchers: Syndikus et al. (93\%) [38], Zietman et al. (73\%) [40], Choo et al. (88\%) [41] and Vargas et al. (52\%) [42].

Three randomized studies (EORTC 22911, SWOG 8794 ARO) proved benefits from postoperative radiotherapy in case of unfavorable prognostic factors. Postoperative radiotherapy improved asymptomatic survival (free of clinical or biochemical evidence of disease), decreased the risk of clinical recurrence [19-24] and influenced overall survival [23].

The Bolla et al. EORTC 22911 study compared the results of postoperative radiotherapy in a group of 502 patients with the results of prostatectomy alone in a group of 503 patients. Postoperative radiotherapy was performed in case of unfavorable prognostic factors, such as extracapsular extension, positive surgical margins and/or seminal vesicles invasion. During 5-year follow-up bPFS was better in the group of patients who underwent radiotherapy (74\% vs. 52.6\%). Clinical PFS was also better in the irradiated group ( $85 \%$ vs. $75 \%$ ). Frequency of recurrence during the 5-year follow-up was significantly lower in the group with adjuvant radiotherapy (5.4\% vs. $15.4 \%$ ). An influence on overall survival was not proved. Toxicity of the treatment was not high and caused treatment discontinuation in $3.1 \%$ of cases. In a control group radiotherapy was used in case of PSA increase $(61.3 \%)$ or locoregional progression (34.4\%). The main objections against the study concern the use of conventional radiation, suboptimal total irradiation doses, including patients with constant increase of PSA (10.7\%), and variation in treatment of recurrences $[19,20]$.

The second randomized study, SWOG 8794, was performed in a group of 473 patients with extracapsular extension, positive margins and/or seminal vesicles infiltration. Patients who underwent radiotherapy were given a dose of 60-64 Gy. The follow-up was 9.7 years. Biochemical PFS (PSA $<0.4 \mathrm{ng} / \mathrm{ml}$ ) was much longer in the irradiated group $(72 \%$ vs. $42 \%$ ). Distant metastasis-free survival was also better in the group with postoperative radiotherapy $(p=0.023)$ [22]. In patients with extracapsular extension, radiotherapy significantly improved bPFS (57\% vs. 22\%) and decreased local recurrence risk ( $8 \%$ vs. $22 \%$ ). Side effects of radiotherapy were insignificant and did not affect patients' quality of life. In the control group $32 \%$ of patients underwent salvage radiotherapy $[21-23,46]$

The third randomized study was performed by the German group ARO 96-02/AUO AP 09/95. The analysis included 385 patients from 22 centers in stage pT3 or with positive margins. One hundred thirty-two patients underwent postoperative radiotherapy and were given $60 \mathrm{~Gy}$ in $30 \mathrm{frac}-$ tions. Patients diagnosed with postoperative PSA increase were classified as showing disease progression and thus given a higher average dose of $66.6 \mathrm{~Gy}$. The follow-up was 40 months. In the irradiated group an improvement of bPFS was noted (72\% vs. 54\%). An influence of radiotherapy on overall survival was not proved. Frequency of recurrence was 16\% vs. $7 \%$ in favor of patients who underwent radiotherapy. The tolerance of irradiation was good [24].

The quoted randomized studies provided evidence that postoperative radiotherapy improves bPFS with an acceptable level of side effects. It is, however, probable that 50\% of patients will be irradiated unnecessarily. On the other hand, waiting for clinical recurrence in case of biochemical progression can cause spread of the disease.

Our study is a retrospective observation and presents results of treatment of 121 patients who underwent radical prostatectomy and postoperative radiotherapy. During 27 months of follow-up the biochemical progression-free survival for the analyzed group was $72 \%$. These results are difficult to compare with others due to the high diversity of the group, which included patients with stage T3 or T4 disease and positive nodes, and due to the relatively short time of observation. In the univariate analysis it was proved that the following factors negatively influenced 3-year bPFS: extracapsular tumor extension, seminal vesicles invasion, Gleason $\geq 7$ and no use of hormonal therapy. Maximum preoperative PSA level, infiltration of vascular-nerve bundles, positive surgical margins, infiltration of adjacent organs and dose of irradiation did not significantly influence bPFS. In the multivariate analysis such factors as advanced TNM stage, no use of postoperative hormonal therapy, lower total irradiation dose and higher maximum pretreatment PSA level were associated with worse bPFS. During the follow-up 29 patients (24\%) experienced biochemical recurrence that appeared 3-52 months (median: 15 months) after the day of surgery. Among them in 18 cases (14.8\%) clinical recurrence was diagnosed. In 13 cases biochemical progression preceded clinical recurrence (on average by 5 months). In the remaining 5 cases biochemical and clinical progression appeared 
at the same time. Such a high percentage of recurrence may result from allowing in the analysis patients with stage T4 disease. In the univariate analysis it was proved that such factors as preoperative PSA > $10 \mathrm{ng} / \mathrm{ml}$, vascular-nerve bundles and adjacent organs infiltration as well as no use of postoperative hormonal therapy negatively influenced 3-year CPFS.

In the light of randomized studies postoperative radiotherapy is a treatment option that should be considered in patients with unfavorable prognostic factors because of its significant local effectiveness and relatively low toxicity, which we confirmed in our observation. Early commencement of radiotherapy can bring better treatment results. Thus good cooperation between urologists and radiation oncologists is required, which was proved by a number of retrospective and prospective studies [14, 19-24, 35, 38, 42, 47].

Radiotherapy is nowadays a widely accepted method of treating prostate cancer patients. Technological progress and constant improvement of irradiating methods have significantly increased oncological effectiveness of this method in recent years. Also increased safety of irradiation and decreased risk of post-irradiation complications constitute significant benefits in treating patients after radical prostatectomy. Although the influence of radiotherapy on patients' quality of life requires further research, acceptance of the method is growing and growing.

The authors declare no conflict of interest.

\section{References}

1. Gibbons RP, Correa RJ, Branner GE, Weissman RM. Total prostatectomy for clinically localized prostate cancer: long-term results. J Urol 1989; 141: 564-6.

2. Zincke H, Oesterling JE, Blute ML, Bergstralh EJ, Myers RP, Barrett DM. Long-term (15 years) results after radical prostatectomy for clinically localized (stage T2c or lower) prostate cancer. J Urol 1994; 154 1850-7.

3. Albertsen PC, Fryback DG, Storer BE, Kolon TF, Fine J. Long-term survival among men with conservatively treated localized prostate cancer. JAMA 1995; 274: 626-31.

4. Walsh PC. Anatomic radical prostatectomy: Evolution of the surgical technique. J Urol 1998; 160: 2418-24.

5. Schroder FH. Prostate cancer: natural history and surgical treatment of localised disease. Eur J Cancer 2001; 37 suppl 7: 127-36.

6. Zincke H, Bergstralh EJ, Blute ML, Myers RP, Barrett DM, Lieber MM, Martin SK, Oesterling JE. Radical prostatectomy for clinically localized prostate cancer: long-term results of 1,143 patients from a single institution. J Clin Oncol 1994; 12: 2254-63.

7. Ward JF, Zincke H, Bergstralh EJ, Slezak JM, Myers RP, Blute ML. The impact of surgical approach (nerve bundle preservation versus wide local excision) on surgical margins and biochemical recurrence following radical prostatectomy. J Urol 2004; 172: 1328-32.

8. Bott SR, Freeman AA, Stenning S, Cohen J, Parkinson MC. Radical prostatectomy: pathology findings in 1001 cases compared with other major series and over time. BJU Int 2005; 95: 34-9.

9. Walz J, Chun FKH, Klein EA, Reuther A, Graefen M, Huland $H$, Karakiewicz PI. Risk-adjusted hazard rates of biochemical recurrence for prostate cancer patients after radical prostatectomy. Eur Urol 2008; 55: 412-21.

10. Touijer K, Secin FP, Cronin AM, et al. Oncologic outcome after laparoscopic radical prostatectomy: 10 years of experience. Eur Urol 2009; 55: 1014-9.

11. Roehl KA, Han M, Ramos CG, Antenor JA, Catalona WJ. Cancer progression and survival rates following anatomical radical retropubic prostatectomy in 3,478 consecutive patients: long-term results. J Urol 2004; 172: 910-4.

12. Han M, Partin AW, Zahurak M, Plantadosi S, Epstein JI, Walsh PC. Biochemical (prostate specific antygen) recurrence probability following radical prostatectomy for clinicallylocalized prostate cancer. Jurol 2003; 169: 517-23.

13. Schellhammer PF. Radical prostatectomy: Patterns of local failure and survival in 67 patients. Urology 1988; 31: 191-7.

14. Anscher MS, Prosnitz LR. Postoperative radiotherapy for patients with carcinoma of the prostate undergoing radical prostatectomy with positive surgical margins, seminal vesicle involvement and/or penetration through the capsule. J Urol 1987; 138: 1407-12.

15. Zietman AL, Edeltsein RA, Coen JJ, Babayan RK, Krane RJ. Radical prostatectomy for adenocarcinoma of the prostate: The influence of preoperative and pathological findings on biochemical diseasefree outcome. Urology 1994; 43: 823-33.

16. Pinto F, Prayer-Galetti T, Gardiman M, Sacco E, Ciaccia M, Fracalanza S, Betto G, Pagano F. Clinical and pathological characteristics of patients presenting with biochemical progression after retropubic prostatectomy for pathologically organ-confined prostate cancer. Urol Int 2006; 76: 202-8

17. Chun FK, Graefen M, Zacharias M, et al. Anatomic radical retropubic prostatectomy-long-term recurrence-free survival rates for localized prostate cancer. World J Urol 2006; 24: 273-80.

18. Shekarriz B, Upadhyay J, Wood DP Jr, Hinman J, Raasch J, Cummings GD, Grignon D, Littrup PJ. Vesicourethral anastomosis biopsy after radical prostatectomy: predictive valuae of prostate-specific antigen and pathologic stage. Urology 1999; 54: 1044-8.

19. Bolla $M$, van Poppel $H$, Collette $L$, et al. Postoperative radiotherapy after radical prostatectomy: a randomised controlled trial (EORTC trial 22911). Lancet 2005; 366: 572-8.

20. Van der Kwast TH, Bolla M, Van Poppel H, et al. Identification of patients with prostate cancer who benefit from immediate postoperative radiotherapy (EORTC trial 22911). J Clin Oncol 2007; 25: 4178-86.

21. Thompson IM Jr, Tangen CM, Paradelo J, et al. Adjuvant radiotherapy for pathologically advanced prostate cancer: a randomized clinical trial. JAMA 2006; 296: 2329-35.

22. Thompson IM, Tangen CM, Paradelo J, et al. Adjuvant radiotherapy for pathological T3NOMO prostate cancer significantly reduces risk of metastases and improves survival: long-term followup of a randomized clinical trial. J Urol 2009; 181(3): 956-62.

23. Swanson GP, Goldman B, Tangen CM, et al. The prognostic impact of seminal vesicle involvement found at prostatectomy and the effects of adjuvant radiation: data from Southwest Oncology Group 8794. J Urol 2008; 180: 2453-7.

24. Wiegel T, Bottke D, Steiner U, et al. Phase III Postoperative Adjuvant Radiotherapy After Radical Prostatectomy Compared With Radical Prostatectomy Alone in pT3 Prostate Cancer With Postoperative Undetectable Prostate-Specific Antigen: ARO 96-02/AUO AP 09/95. J Clin Oncol 2009; 27: 2924-30.

25. Ward JF, Slezak JM, Blute ML, Bergstralh EJ, Zincke H. Radical prostatectomy for clinically advanced (cT3) prostate cancer since the advent of prostate-specific antigen testing; 15 year outcome. BJU Int 2005; 95: 751-6.

26. Valicenti L, Gomella M, Ismail S, Mulholland R, Petersen RO, Corn BW. Effect of higher radiation dose on biochemical control after radical prostatectomy for $\mathrm{PT} 3 \mathrm{NO}$ prostate cancer. Int Radiat Oncol Biol Phys 1998; 42: 501-6.

27. Leibovich BC, Engel DE, Patterson DE, Pisansky TM, Alexander EE, Blute ML, Berqstralh EJ, Zincke HG. Benefitof adjuvant radiation therapy for localized prostae cancer with positive surgical margin. J Urol 2000; 163: 1178-82.

28. Catton C, Gospodarowicz M, Warde P, Panzarella T, Catton P, McLean M, Milosevic M. Adjuvant and salvage radiation therapy after radical prostatectomy for adenocarcinoma of the prostate. Radiother Oncol 2001; 59: 51-60.

29. Vincini FA, Ziaja EL, Kestin LL, Brabbins DS, Stromberg JS, Gonzales JA, Martinez AA. Treatment outcome with adjuvant and salvage irradiation after radical prostatectomy for prostate cancer. Urology 1999; 54: 111-7.

30. Zelefsky MJ, Aschkenasy E, Kelsen S, Leibel SA. Tolerance and early outcome of postprostatectomy three-dimensional conformal radiotherapy. Int J Radiat Oncol Biol Phys 1997; 39: 327-33. 
31. Schild SE. Radiation therapy (RT) after prostatectomy: The case for salvage therapy as opposed to adjuvant therapy. Int I Cancer 2001; 96: 94-8.

32. Forman JD, Velasco J. Therapeutic radiation in patients with a rising post- prostatectomy PSA level. Oncology 1998; 12: 33-47.

33. Morris MM, Dallow KC, Zietman AL, Park J, Althausen A, Heney NM, Shipley WU. Adjuvant and salvage irradiation following radical prostatectomy for prostate cancer. Int J Radiat Oncol Biol Phys 1997; 38: 731-6.

34. Pollack A, Smith L. Adjuvant external beam radiation therapy postprostatectomy. Lippincott Williams \& Wilkins; Philadelphia 2002.

35. Petrovich Z, Lieskovsky G, Langholz B, Fromenti S, Baert L, Streeter O, Skinner DG. Radical prostatectomy and postoperative irradiation in patients with pathological stage C (T3) carcinoma of the prostate. Int J Radiat Oncol Biol Phys 1998; 40: 139-47.

36. Wiegel T, Bressel M Carl UM. Adjuvant radiotherapy following radical prostatectomy-results of 56 patients. Eur J Cancer 1995; 31A 5-11.

37. Schild SE, Wong WW, Grado GL, Halyard MY, Nowicki DE, Swan son SK, Larson TR, Ferringi RG. The results of radical retropubic prostatectomy and adjuvant therapy for pathologic stage C prostate cancer. Int J Radiat Biol Phys 1996; 34: 535-41.

38. Syndikus I, Pickles T, Kostashuk E, Sullivan LD. Postoperative radiotherapy for stage $\mathrm{pT} 3$ carcinoma of prostate: improved local control. J Urol 1996; 155: 1983-6.

39. Valicenti RK, Gomella LG, Ismail M, Strup SE, Mulholland SG, Dick er AP, Petersen RO, Newschaffer CJ. The efficacy of early adjuvant radiation therapy for PT3NO prostate cancer: a matched-pair analysis, Int J Radiat Oncol Biol Phys 1999; 45: 53-8.

40. Zietman AL, Coen JJ, Shipley WU, Althausen AF. Adjuvant irradiation after radical prostatectomy for adenocarcinoma of prostate: analysis of freedom from PSA failure. Urology 1993; 42: 292-9.

41. Choo R, Hruby G, Hong J, et al. Positive resection margin and/or pathologic T3 adenocarcinoma of prostate with undetectable postoperative prostate-specific antigen after radical prostatectomy: to irradiate or not? Jnt J Radiat Oncol Biol Phys 2002; 52: 674-80.

42. Vargas C, Kestin LL, Weed DW, Krauss D, Vicini FA, Martinez AA Improved biochemical outcome with adjuvant radiotherapy after radical prostatectomy for prodtate cancer with poor pathologic features. Int J Radiat Oncol Biol Phys 2005; 61: 714-24.

43. Anscher MS, Robertson CN, Prosnitz LR. Adjuvant radiotherapy for pathologic stage T3/4 adenocarcinoma of the prostate. Ten year update. Int J Radiat Biol Phys 1995; 33: 37-43.

44. Nudell D, Grossfeld G, Weinberg V, Roach M, Carrol P. Radiotherapy after radical prostatectomy: treatment outcomes and failures patterns. Urology 1999; 54: 1049-57.

45. Caraffini B, De Stefani A, Vitali E, Margi E, Tonoli S, Frata P, Gatta R, Magrini SM. Postoperative radiotherapy after radical prostatectomy for prostate carcinoma: the experience of the Brescia Radium Institute. Radiol Med 2006; 111: 741-7.

46. Swanson GP, Thompson IM, Tangem C, et al. Phase III randomized study of adjuvant radiation therapy versus observation in patients with pathologic T3 prostate cancer (SWOG 8794). Int J Radiat Oncol Biol Phys 2005; 63 (Suppl 1): S1.

47. Gibbons RP, Cole BS, Richardson RG, Correa RJ Jr, Brannen GE, Mason JT, Taylor WJ, Hafermann MD. Adjuvant radiotherapy following radical prostatectomy: results and complications. J Urol 1986; 135: $65-8$

\section{Address for correspondence}

Ewa Ziółkowska MD, PhD

Department of Radiotherapy I

Oncology Centre - prof. Franciszek Łukaszczyk Memorial Hospital

Romanowskiej 2

85-796 Bydgoszcz

e-mail: ziolkowskae@co.bydgoszcz.pl

Submitted: 9.05 .2012

Accepted: $\quad 8.05 .2013$ 